\title{
Social work practice during the COVID-19 state of emergency in Spain
}

\author{
Alfredo Hidalgo Lavié1 , Ana M González Ramos², \\ and Ana Isabel Lima Fernández ${ }^{3}$
}

\begin{abstract}
Spain was very hard hit by the pandemic and was also one of the first to implement the strictest confinement measures. Social services are a key sector for alleviating the social impacts on citizens. We conducted an online survey to investigate the work that has been done by social workers employed by the Community of Madrid and the Madrid City Council. Respondents felt stressed and bewildered by the lack of coordination between the different public administrations responsible for the care and health issues caused by COVID-19. They have had to manage support and assistance related to food and hygiene, to provide emotional help, to access information on the pandemic to pass on to users, and to allocate the financial aids provided by the administration. Teleworking became the main working method, coordinating and interacting with users online as a consequence of mobility restrictions and social distancing.
\end{abstract}

Keywords:

1. National Distance Education University (UNED)

2. Universidad Pablo de Olavide

3. Director of the Social Service in the Mancomunidad of Madrid

Address for correspondence: amgonram@upo.es

Date of first (online) publication: 3rd August 2021 


\section{Introduction}

Spain was one of the European countries most affected by the pandemic during the first outbreak and, thus, decreed some of the strictest confinement measures (EUROFOUND, 2020). The impact of the global pandemic in Spain includes a substantial economic impact (GDP drop of $-10.9 \%$, when the EU average is $-8.7 \%$, according to the European Parliament Newsletter, 2020). According to the EU Labour Force Survey (28 April 2020), poverty and social exclusion have worsened, where 1.1 million families have unemployed members and 600,000 households have zero income. The Spanish government considered social services a key sector for alleviating the social impacts of the country's healthcare and confinement crisis (INAP, 2020). This has represented a great challenge for social workers, as the quarantine obligated them to take on larger caseloads and handle a wider variety of demands from vulnerable groups. They also had to cope with a new working environment, as teleworking became mandatory due to the special measures in force from 15 March to 20 May 2020 (Royal Decree [RD henceforth] 463/2020 of 14 March declaring the state of emergency to manage the health crisis caused by COVID-19).

In this article, empirical data will show that social workers identify an increase in new demands and new at-risk groups as a consequence of the crisis. In addition, they have had to handle these issues from a work setting plagued by uncertainty, coping with an emergency situation never experienced before. Their work has faced ethical implications brought on by having to manage complex inequities due to the large number and profiles of citizens who have experienced precariousness because of the COVID-19 pandemic (Banks et al., 2020). They have needed to deal with dire situations to fairly distribute the emergency resources among the vulnerable population already in the social service system and the new at-risk populations that started applying and asking for support.

Teleworking has become essential to help curb the spread of the disease and the social work field is no exception (Banks et al. 2020; Dauti et al. 2020). Like the rest of the population, most social workers were at home under confinement, taking on this spike in demands during the pandemic. Their working methods have been quite difficult, since face-to-face communication had always been deemed an important factor in the social work profession. Online methods in professional practice are not new, but social workers may have felt reluctant to work remotely because they were accustomed to interacting with users in person (Goldkind and Wolf, 2015; Hidalgo and Lima, 2018; Berg et al., 2018; Urzi Brancati et al., 2019). It created a new challenge, since social workers have had a steep learning curve for using technology intensively in their daily tasks: working online to handle and manage citizens' petitions, holding coordination meetings with colleagues, and assisting service users while working remotely (INAP, 2020; Dominelli, 2020). 


\section{Spanish policy framework and legislative action on social work practice to deal with the pandemic}

In accordant with national and international recommendations (Communication from the Commission - Implementing the Community Lisbon programme - Social services of general interest in the European Union SEC(2006)516/COM/2006/0177 final and the Spanish Constitution, article 128.2, transferred to the region of Madrid by Law 11/2003 of 27 March on Social Services), the Spanish government had implemented a legal framework and formal protocols to cope with special times of crisis and emergency situations for the social service profession. The World Health Organization's declaration of a 'global pandemic' in March 2020 led to RD 463/2020 of 14 March 2020 declaring the state of emergency in Spain for handling the health crisis caused by COVID-19. Restrictions to citizens' free movement have affected attending school and travelling into workplaces, creating a severe impact on households both economically and socially. The government launched several economic benefit packages to relieve citizens' immediate needs (Royal Decree-Law [RD-L henceforth] 8/2020 of 17 March 2020 on extraordinary urgent measures to manage the economic and social impact of COVID-19).

Social services' roles have usually always included the function of trying to improve the vulnerable population's condition, and these days legal regulations and policies have strengthened this area of social work. Order SND/295/2020 of 26 March 2020 on new human resources measures for social services states: 'all people working in social services, regardless of whether they were already teleworking, should be available at any time for face-to-face tasks, except those people who are isolated at home because of COVID-19'. In addition, the government declared social services a critical and essential operational area, as well as every centre and entity that provides support according to the Reference Catalogue of Social Services approved on 16 January 2013 by the Regional Council Agreement on Social Services and the System for the Care and Autonomy of Dependent People. Social workers are in charge of social work records and are the main public faces for providing support to users, ensuring the coordination and coherence of practices between the welfare system and the entire process of covering basic needs. Likewise, the Spanish Ministry of Social Rights and 2030 Agenda published its Technical Document on Recommendations for Political Leaders and Managers of Primary Care Social Services to cope with COVID-19 (6 April 2020), which details the need to reorganise the social service system.

Despite the allocation of additional funding to social services, as set out in the aforesaid RD-L 8/2020, financial resources did not reach social work institutions as quickly as the unprecedented demands from the vulnerable population (INAP, 2020). Social workers had to juggle new benefits for electricity, housing and employment for citizens. In the early days of the pandemic, social workers had to cope with assisting the population with basic needs, had to urgently organise scant resources, 
working overtime and overcoming stress and uncertainty, even calling upon NGOs and charity organisations for support (Dauti et al., 2020). They also had to use digital technologies intensively: teleworking from home, with colleagues sharing their questions on social networks (mailing lists, virtual chats and video calling), while operating online with users (INAP, 2020). Completely unlike the health personnel who received nightly ovations and social recognition from citizens, social workers garnered none of this praise (INAP, 2020; Banks et al., 2020).

\section{Methodology}

With the aim of finding out about social workers' working conditions, we decided to conduct an online survey during the pandemic. According to official statistics, the Spanish Ministry of Health, and the Carlos III Institute, Madrid was the region with the highest number of deaths and infection rates in Spain. Thus, we decided to centre on this region, focusing on the social worker population in the Social Service Units of the Community and City Council of Madrid.

The study population targeted social service workers employed in both local and regional administrations, that is, working for Community Social Services and the City Council Districts. The total population of social workers in Madrid (555 working in primary care settings at regional entities and 600 in the districts of the municipality) is comprised of 1155 people. Therefore, the response rate was $15.67 \%$, $\mathrm{p} / \mathrm{p}=0.5, \mathrm{e}=6.7$, with a significance level of $95 \%$. The online survey was distributed via professional contact lists and social-work social media sites in the Madrid region. The questionnaire was conducted from 11 May to 8 June 2020, the first period of the pandemic and household confinement.

We conducted a preliminary test with social workers in other autonomous communities, who were not included in our target population, although they were having similar experiences, to prove the validity of the questionnaire. Their comments helped to fine-tune several questions and, especially, to resolve technical issues in the questionnaire (how some questions were displayed and simplifying a few texts and response categories). These changes were made to less than 5\% of the questionnaire.

Survey administration was done on Google Forms and disseminated to mobile phones or other internet-connected devices. Responding was voluntary and the beginning of the online questionnaire contains ethical information about the research objective, scientific purpose, and the anonymous and confidential agreement of the research group for using their personal data.

The closed questionnaire contains 25 questions, divided into five different subject-based sections: 1) evaluation of the organisation of social services and political actions of the different competent institutions (central, regional and local 
governments), 2) type of care and provision of new services to citizens, 3) changes to the working environment to digitalise social work, 4) assessment of how ethical the measures employed during this emergency situation were, and the likelihood that these changes to social work practice will be permanent and transferred into the post-crisis scenario, and 5) sociodemographic characteristics. The questions were drafted based on the experiences collected from social workers' practices, using the same questions when it was feasible, for instance, the catalogue of Spanish Social Service Units, working environment and sociodemographic features.

The subsequent data analysis was performed using SPSS Statistics software. For the purpose of this work, we conducted a descriptive analysis so that we could report on the fast changes occurring in social work practices. This article is primarily centred on describing the types of services most requested by the user population, assessing the changes compared to the volume of requests habitually made. This lets us present the new demands on social workers, the new services that have emerged, and the new groups identified (section 2). We also added information on questions in sections 1 and 3 regarding the coordination between administrations. A corollary to this work is professionals' vision of their work in the future (section 4) with regard to providing care for users in a context of precariousness and crisis (Beck, 1992; Webb, 2006; Lorey, 2015; Golightley and Holloway, 2020).

\section{Results}

We introduce this section with a short note characterising the population that answered the online questionnaire. As was to be expected in a highly-feminised sector $^{1}$, the large majority of responses were from female social workers (86.7\%) between 36 and 55 years old (71.8\%), with only $13.8 \%$ younger than 36 . Almost half (45.3\%) have extensive work experience (from 16 to 38 years) and only $16 \%$ have fewer than 5 years in the field.

\section{Provision of services}

According to respondents, the majority of social service areas has increased, particularly for basic needs and primary care (in excess of 90\%), housing (greater than $85 \%$ ) and health (nearly $80 \%$ ). Other services like civil protection, gender violence and services for the homeless have also increased to above 50\% compared to the number of petitions regularly handled in the course of their services. 
Figure 1. Increase in requests for assistance compared to regular demand, by service areas

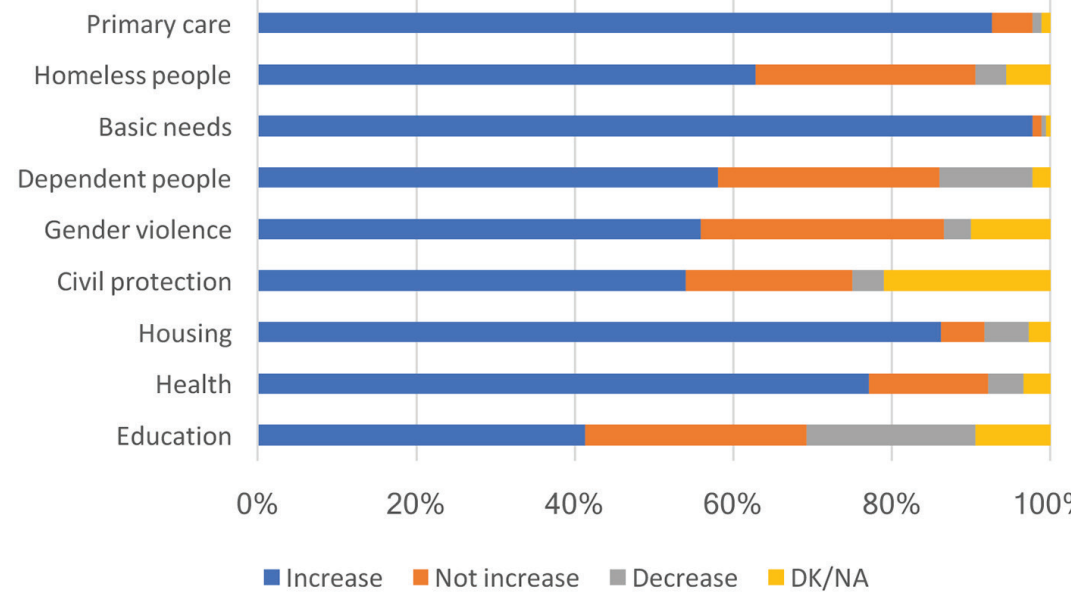

Source: own elaboration based on the COVID-19 social workers questionnaire

In short, the services that social workers provided most during the state of emergency were related to food and hygiene (over 90\%), emotional support and special information about the disease (some 80\%), and other financial aids. Conversely, school supplies (related to virtual education) and services related to dependent people have been least demanded. Medical requests and telecommunication assistance (such as recharging mobiles) grew only slightly, with values close to normal.

Figure 2. Services provided compared to past demand

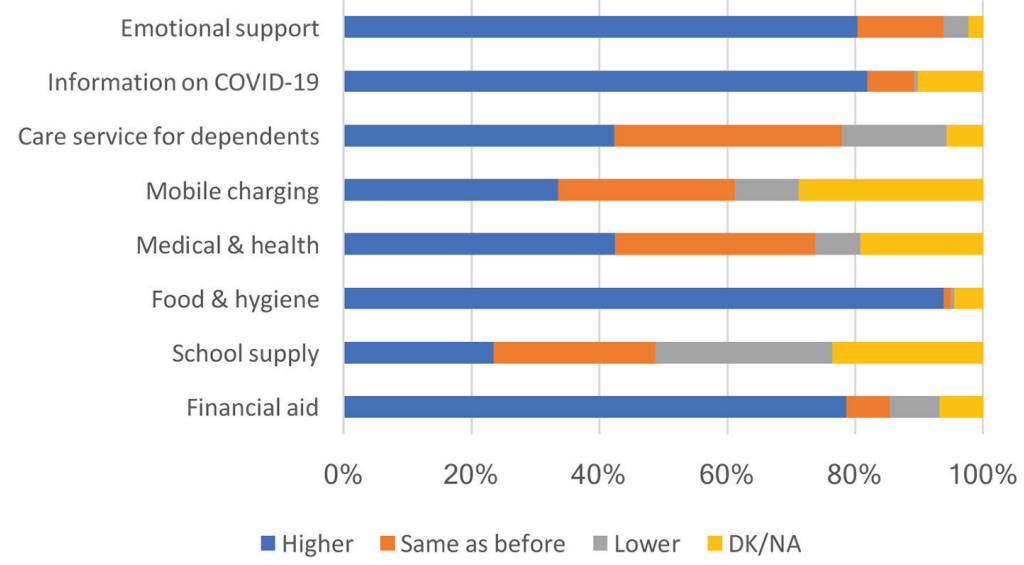

Source: own elaboration based on the COVID-19 social workers questionnaire 
One aspect they pointed out is that new demands have led to the creation of new types of benefits and new types of services (RD 463/2020 and RD-L 8/2020, as well as the monitoring report on the COVID-19 impact published by INAP, September 2020). The majority are related to the home delivery of foods and personal hygiene products, as well as help applying for the extraordinary aids implemented by all administrations (central, regional and local governments). They also mentioned pharmaceuticals and recharging tablets or mobiles for internet connection, which became necessity goods during confinement because of the digitalisation of work, school and life in general.

Telephone care services were mentioned by respondents as the primary method to give users psychosocial and emotional counselling for their fear, solitude, pain and grief. Queries related to handling applications for assistance and financial benefits also revealed the feeling of emergency and vulnerability perceived by the people of Madrid. One significant fact that highlights the severity of the emergency has been the appearance of new users as a consequence of the impoverishment of Spanish households (INAP, 2020). Over 90\% of respondents confirmed that they have identified a higher volume of people requesting resources, all of them new beneficiaries who had never before turned to community social service centres.

NGOs and charity associations have played a central role for distributing resources and assisting vulnerable families round the world (Amadasun, 2020). The increased participation of the third sector in Spain is related to delays in receiving resources, and the priority of social workers to remedy citizens' vulnerable situations as quickly as possible. And, respondents believed the three government levels - state, regional and local administrations - performed poorly in managing the crisis. For example, some $60 \%$ of social workers stated that they did not receive any support from the regional administration, although the city council and central administration received better scores. The majority agreed that there has been no coordination between administrations with regard to speeding up procedures and providing information on how to distribute public resources.

\section{Working conditions and opinions on how the state of emergency impacted social workers}

Social workers continued to perform their jobs during the state of emergency (although $11 \%$ of respondents were on sick leave when they answered the questionnaire). Only $20 \%$ carried out their functions face-to-face, meaning that the large majority did their regular work remotely (see Figure 3). Over three quarters admitted that they have had to use their own phones and internet access, and one of three social workers has used their own programs to manage work meetings and organise their work. 
Figure 3. Resources they had during confinement

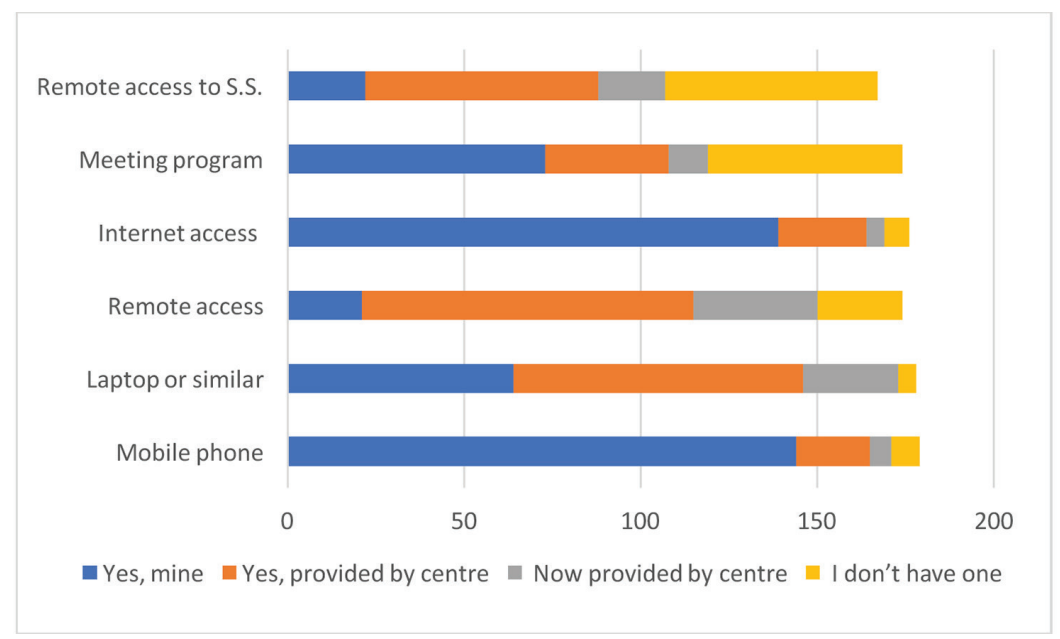

Source: own elaboration based on the COVID-19 social workers questionnaire

About whether the series of economic measures have been enough to reduce the effects of the emergency, over half the social workers (61\%) believe that funding has increased considerably, although it has still been clearly insufficient. The distribution of personal protective equipment (PPE) has been significant, but also not enough (62\%). 46\% consider that the number of qualified personnel has increased considerably, or that there was enough staff before (21.5\%). Over $50 \%$ of the people surveyed feel that, despite this increase, there is still a shortage of programmes with specialised services, and $40 \%$ estimate that collaborations with the third sector must be increased in terms of their number and scope.

The state of emergency has engendered a new scenario for social workers, which is why we included a question related to ethical considerations on their work performance during this time (Table 1). Faced with the high-risk situations they have dealt with, the majority of respondents (56\%) expressed agreement with prioritising vulnerable groups over the general population that was now requesting support, keeping preferential treatment for previous users. Conversely, $45 \%$ of respondents said that they 'reluctantly agreed' to grant resources more closely related to welfare or charity functions than modern social services (meaning, creating an initial diagnosis guaranteed by their professional code: investigation of background, nonstigmatisation, data protection, avoiding duplicity, and preserving social equality rights).

These reservations about taking specific actions and/or decisions became clear during the handling process, as they were obligated to grant strictly assistance resources or deny the resources requested when people did not have the correct official documents. In this regard, one of four social workers has been reluctant to 
assign these resources, although $23 \%$ stated that this was not their experience at all, which may show that the population - despite their vulnerability - has used social services properly. They were also reluctant to inappropriately favour users (30\%), or, conversely, did so without any ethical dilemma (28\%).

Table 1

Ethical considerations on their work during the pandemic

\begin{tabular}{|l|l|l|l|l|l|}
\hline & I did it & $\begin{array}{c}\text { I did it } \\
\text { reluctantly }\end{array}$ & $\begin{array}{c}\text { I did not } \\
\text { do it }\end{array}$ & $\begin{array}{c}\text { That was } \\
\text { not my } \\
\text { experience }\end{array}$ & $\begin{array}{c}\text { DK/ } \\
\text { NA }\end{array}$ \\
\hline $\begin{array}{l}\text { Granting emergency aid for } \\
\text { people not in this situation }\end{array}$ & 29.3 & 20.4 & 23.8 & 23.2 & 3.3 \\
\hline $\begin{array}{l}\text { Granting charitable or } \\
\text { merely assistance resources }\end{array}$ & 29.8 & 44.8 & 7.7 & 14.9 & 2.8 \\
\hline $\begin{array}{l}\text { Denying resources due } \\
\text { to not having the proper } \\
\text { official documents }\end{array}$ & 19.3 & 26.0 & 23.2 & 27.6 & 3.9 \\
\hline $\begin{array}{l}\text { Giving preferential } \\
\text { treatment for people } \\
\text { in vulnerable, but not } \\
\text { emergency, situations }\end{array}$ & 55.8 & 18.8 & 8.8 & 13.3 & 3.3 \\
\hline $\begin{array}{l}\text { Risk of inappropriately } \\
\text { favouring users }\end{array}$ & 27.6 & 30.4 & 17.1 & 22.1 & 2.8 \\
\hline $\begin{array}{l}\text { Balance in the fair } \\
\text { distribution of limited } \\
\text { resources }\end{array}$ & 25.4 & 26.0 & 21.0 & 24.9 & 2.8 \\
\hline $\begin{array}{l}\text { Denying aids due to } \\
\text { considering them structural } \\
\text { needs }\end{array}$ & 18.2 & 21.5 & 24.9 & 32.0 & 3.3 \\
\hline
\end{tabular}

Source: own elaboration based on the COVID-19 social workers questionnaire

This experience has been useful as an unplanned type of 'proof-of-concept test' with respect to the need to make changes in managing social services in light of the social transformations occurring in the contemporary era and related to crisis management (Webb, 2006; Lorey, 2015; Banks et al., 2020). So, the survey asked social workers how they would rate the present experience and how they imagined the future scenario. According to Figure 4, almost 90\% thought that the most important support would be related to unemployment (89\%), housing (70\%), primary care (68\%), poverty (68\%), emotional and grief counselling (67\%), attending to emergencies (59\%) and community services (50\%). With values below 50, they think care methods for the elderly must change (46\%), as well as the handling of 
gender violence (42\%), group interventions (25\%), other dependent groups (17\%), and drug addiction (less than $17 \%$ ).

Figure 4. Assessment of the social service fields that will be most in demand in the post-emergency period

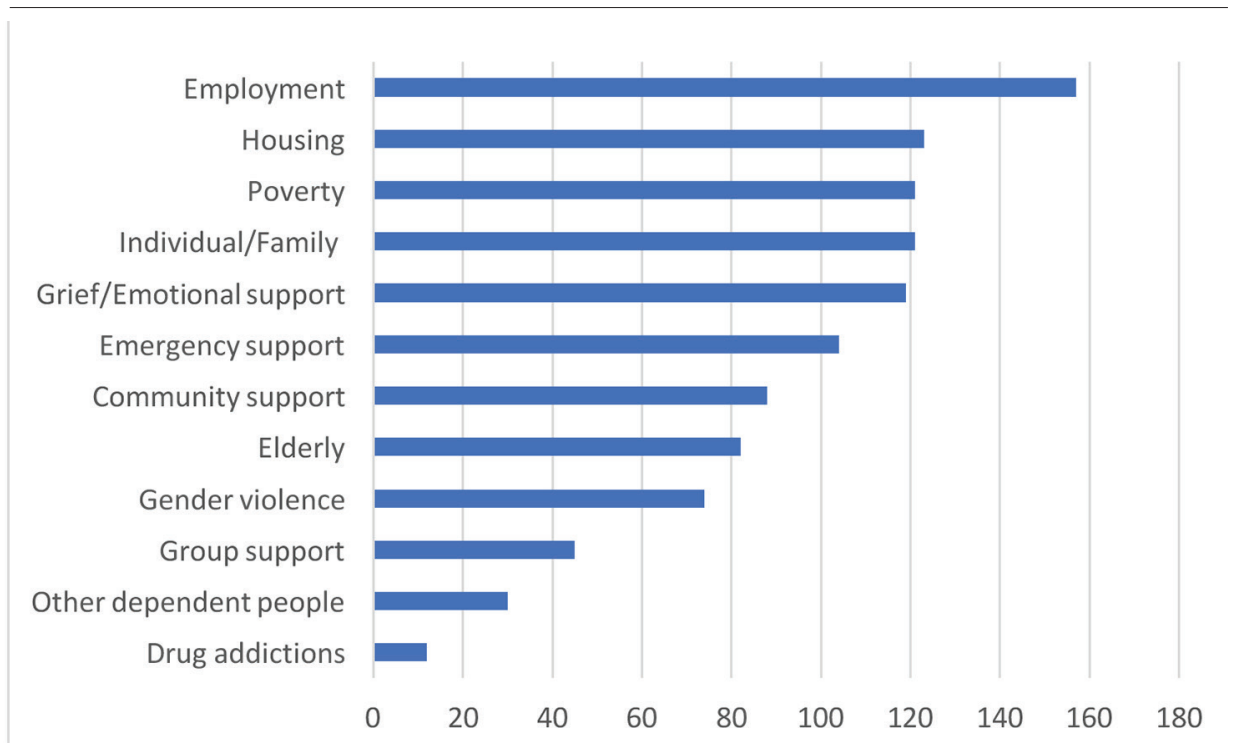

Source: own elaboration based on the COVID-19 social workers questionnaire

To cope with this new context, $75 \%$ considered it essential to plan how social services will handle likely new outbreaks of pandemics, and 55\% asked for PPE distribution for staff protection; to a lesser degree, $40 \%$ thought social care and public health coordination must be strengthened, $28 \%$ called for a new model for the elderly, and 20\% stated that there should be compliance with the benefits set out in the regional legislation approved by the Assembly of Madrid (autonomous community) in May 2013. Finally, 15\% of respondents said prevention measures must be increased for hate/discriminatory behaviours, and 6\% claimed care for child and youth protection, although these last two areas are considered to have less priority in the future scenario.

With regard to methodology, practically all respondents (97\%) believed that the coordination of social care and public health will be necessary (Figure 5).

Lastly, with regard to the teleworking practices that they will definitely have to accept after the COVID-19 outbreak, this area merits mention because of Spanish social workers' previous reluctance to work remotely, as Hidalgo and Lima revealed (2018). Of all respondents, $80 \%$ assume that teleworking will become the primary working method for social work. 
Figure 5. Assessment of methodological changes in social work practices

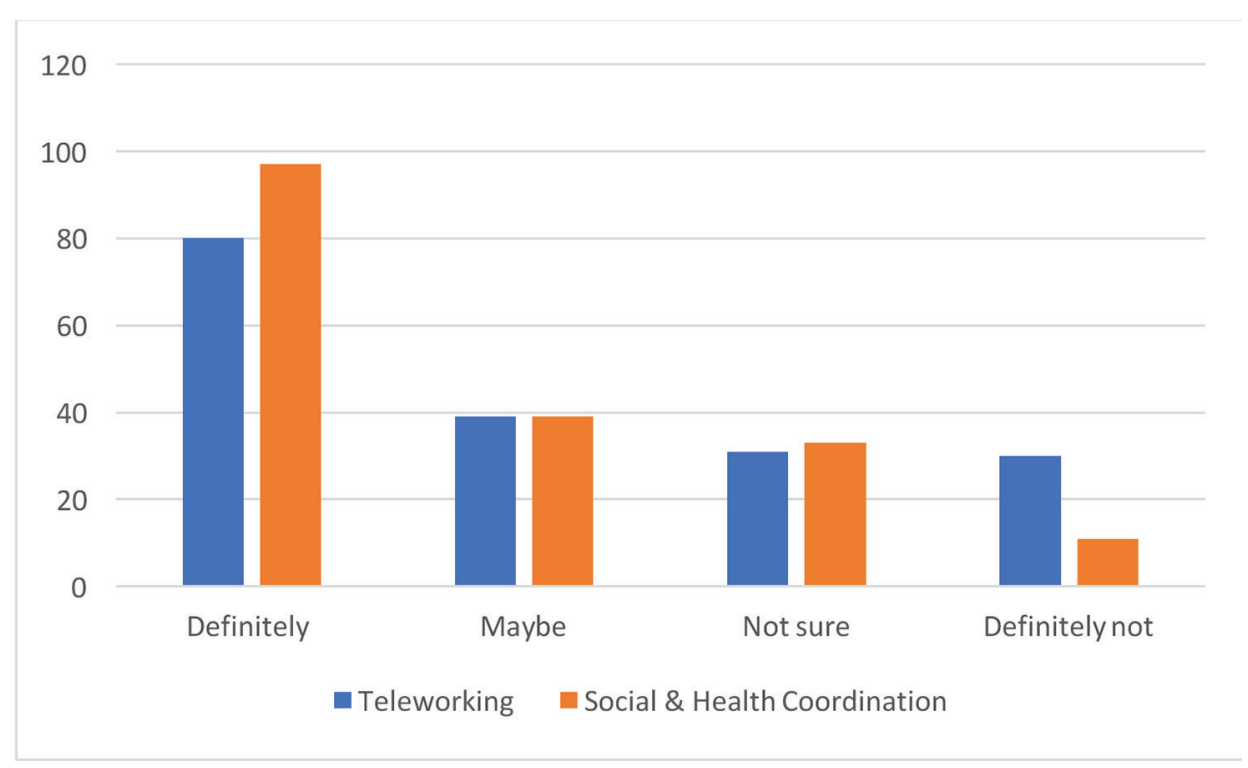

Source: own elaboration based on the COVID-19 social workers questionnaire

\section{Conclusions}

Spain has been extremely hard-hit by the pandemic (EUROFOUND, 2020; European Parliament Newsletter, 2020), both in health and economic terms, making social work emerge as a fundamental field for overcoming the crisis. Moreover, the feeling that we are living in a world in permanent crisis, which affects everyone and creates a perception of precariousness, encourages new responses from social services (Banks et al., 2020; Dominelli, 2020; INAP, 2020; Nissen, 2020).

The crisis is causing polarisation and inequalities among social groups, very different from how social exclusion was handled in the past. COVID-19 has increased the precarious, nearly endemic, situation of social services in Spain (INAP, 2020). The emergency situation has created uncertainty and longer working hours for some specific workers, such as social service employees. Our results support the qualified opinion of Spanish social services reflected in the press and in reports (i.e., INAP, 2020). In this regard, data studies confirm the demands of social workers' representatives: coordinate and plan for future emergency situations. Furthermore, these results are confirmed as a global trend throughout the world (Banks et al., 2020; Dauti et al., 2020).

Social workers in Madrid, both in the Community and at the City Council, 
have stated that the majority of social service areas has increased during the emergency, especially: coverage of basic needs, primary care, housing and health (also corroborated in the Monitoring Report by the National Institute of Public Administration, INAP, 2020). First and foremost, they have had to manage benefits and assistance related to food and hygiene, emotional support and general information on the pandemic, as well as all financial aids allocated by the administration. The demands they have had to handle during the months of confinement have been extraordinary and urgent, along with acquiring medicines, tablets and mobile charging devices.

Practically all social workers have attended to a higher volume of people applying for resources, many of them new users of the social service system, either unemployed or involved in 'temporary collective redundancy schemes' (ERE/ERTE in Spanish) due to the pandemic crisis (INAP, 2020, also referred to this). This has led to greater participation from NGOs, social networks and charity organisations. During this time, social workers have had to provide assistance (the social workers themselves differentiated this assistance from their functions based on well-founded expert decisions) characterised by urgent decision making, instead of careful and coordinated professional assessments that ensure a fair distribution of resources. For example, INAP (2020) concluded that the pandemic has been a setback for the whole welfare state and the social work system in particular.

The respondents are not satisfied with the administrations' actions at any of their three territorial divisions, essentially due to lacking enough support and information in a setting with priority needs. From the social workers' point of view, the most important problem is definitely the lack of coordination between administrations, and the need for joint work to streamline and speed up procedures and the information required to manage public resources in an emergency. On the one hand, as respondents stressed, social care and public health coordination is becoming increasingly more important, given that pandemic and emergency settings will become more frequent (Fan et al., 2018; Nissen, 2020). On the other, social work is becoming progressively more urgent because new needs will emerge from future emergency contexts (for example, related to aids for online working and schooling), as well as different vulnerable populations with profiles yet to be considered (for example, people who had previously received financial resources, were employed or skilled, from the informal economy or service sector).

Thus, we must hope that convenient and similar modifications are also made to social workers' working methods and practices, so that their interventions can be optimal. Teleworking will become increasingly more frequent in social work practice, and the health crisis, which has confined them to their homes, undoubtedly contributes to reducing any lingering reservations they still had about this method. Further, and given the current circumstances, this model will also let them keep doing their jobs under the safest and healthiest conditions possible.

As scholars are just beginning to state (Banks et al., 2020; Dauti et al., 2020; 
Dominelli, 2020; Nissen, 2020), social work needs a plan to face similar future crises that can cope with citizens' stark vulnerability with well-defined and increased resources, ethical guidelines to protect practitioners and users, and technical apps and competences to deal with teleworking, when necessary. Likewise, stakeholders should take action to highlight and recognise the social worker group and strengthen their links with the community. According to the results of this work, the most important changes that social work must face in the future include: the need to adapt methodologies to teleworking, greater participation from the third sector, and greater social care and public health coordination between the administrations and the private sector (for-profit or not), essentially to handle foreseeable needs related to unemployment and housing.

However, we need to inquire into these same questions in the post-COVID scenario to see if their opinions have changed. This is one limitation of this study, as it took a snapshot of a precise time, severely influenced by the crisis, when social workers were doing their work under tough and adverse conditions. A new study targeting the social worker population is necessary to check how lasting or temporary their behaviours have been and what their opinions are today, then comparing both results. Social work would also benefit from further exploration of making quick responses in a crisis context, as the COVID-19 emergency has necessitated, so similar studies will be helpful for facing the future. One contribution of this study is that it is among the first studies centring on this forgotten group of front-line workers who have been involved since the very beginning of the crisis.

\section{Note}

According to Eurostat data, 83.5\% of European social work professionals were women in 2019, when the number of females employed as social workers increases to $85.9 \%$ in Spain.

\section{Acknowledgements}

We want to thank the social workers who responded to this questionnaire for their time, as well as the two anonymous reviewers and the publishers of this journal for their valuable comments that qualitatively improved this article. M. Antonia de Frutos also merits special thanks for her help in disseminating this survey. Finally, we are grateful to Mary T. Bauer, who translated the content of this work into English. 


\section{References}

Amadasun, Solomon (2020) COVID-19 pandemic in Africa: What lessons for social work education and practice? International Social Work, doi:10.1177/0020872820949620

Banks, Sarah, Tai Cai, Ed de Jonge, et al. (2020) Practising ethically during COVID-19: Social work challenges and responses. International Social Work, 63, 5, 569-583. doi:10.1177/0020872820949614

Beck, Ulrich (1992) Risk Society: Towards a New Modernity. London: Sage.

Berg, Janine, Marianne Furrer, Ellie Harmon, Uma Rani and M. Six Silberman (2018) Digital Labour Platforms and the Future of Work: Towards decent work in the online world. International Labour Organization.

Dauti, Marsela, Elona Dhëmbo, Erika Bejko, and M. Allmuça (2020) Rethinking the transformative role of the social work profession in Albania: Some lessons learned from the response to COVID-19. International Social Work, 63, 5, 640-645. doi:10.1177/0020872820940356.

Dominelli, Lena (2020) A green social work perspective on social work during the time of COVID19. International Journal of Social Welfare, 30, 1, 7-16.

EUROFOUND (2020) Living, Working and COVID-19. EUROFOUND https://www.eurofound. europa.eu/publications/report/2020/living-working-and-covid-19.

European Parliament (2020) Covid-19 Newsletter 2: Exit strategy. ECON, EMPL, ENVI, ITRE and IMCO in Focus. COVID-19 Newsletter 08-07-2020

Fan, Victoria Y., Dean T. Jamison, and Lawrence H. Summers (2018) Pandemic risk: How large are the expected losses? Bulletin of the World Health Organization, 96, 129-134, http:// dx.doi.org/10.2471/BLT.17.199588.

Goldkind, Lauri, and Wolf, Lea (2015) A Digital environment approach: Four technologies that will disrupt social work practice. Social Work, 60, 1, 85-87, doi: 10.1093/sw/swu0 45.

Golightley, Malcolm, and Margaret Holloway (2020) Social Work in the time of the Covid-19 pandemic: all in this together? The British Journal of Social Work, 50, 3, https://doi. org/10.1093/bjsw/bcaa213

Hidalgo Lavié, Alfredo, and Ana I. Lima Fernández (2018) New social intervention technologies as a challenge in social work: IFSW Europe perspective. European Journal of Social Work, 21, 6, 824-835, DOI: 10.1080/13691457.2018.1423553

INAP (2020) Los Servicios Sociales ante la pandemia: Retos, Desafíos y respuestas hacia la nueva normalidad. Monitor de Impacto de la COVID-19 sobre los Servicios Sociales. Report from September 2020 by the Spanish National Institute of Public Administration.

Lorey, Isabell (2015) State of Insecurity: Government of the precarious. New York: Verso.

Ministerio de Derechos Sociales y Agenda 2030 (2020). Documento Técnico de Recomendaciones para Responsables Políticos y Personal Directivo de los Servicios Sociales de Atención Primaria ante la crisis por COVID-19. https://www.mscbs.gob.es/ssi/familiasInfancia/ ServiciosSociales/docs/Covid19/Rec_politicos.pdf

Nissen, Laura (2020) Social Work and the future in a post-Covid 19 World: A foresight lens and a call to action for the profession. Journal of Technology in Human Services, 38, 309-330 
Urzi Brancati, Cesira, Annarosa Pesole, and Enrique Fernandez Macias (2019) Digital Labour Platforms in Europe: Numbers, Profiles, and Employment Status of Platform Workers. Publications Office of the European Union: ILO DOI: 10.2760/16653

Webb, Stephen A. (2006) Social Work in a Risk Society: Social and political perspectives. Basingstoke: Palgrave Macmillan 